\title{
Curcumin Extract as a Green Inhibitor of Leaching from Aluminum Cookware at Quasi-Cooking Conditions
}

\author{
Layla A. Al Juhaiman \\ Chemistry Department, Faculty of Science, King Saud University, Riyadh, KSA \\ Email: Ijuhiman@ksu.edu.sa
}

Received 29 February 2016; accepted 20 March 2016; published 23 March 2016

Copyright (C) 2016 by author and Scientific Research Publishing Inc.

This work is licensed under the Creative Commons Attribution International License (CC BY). http://creativecommons.org/licenses/by/4.0/

(c) (i) Open Access

\begin{abstract}
Curcumin aqueous extract is used successfully as a green corrosion inhibitor at quasi-cooking conditions $\left(90^{\circ} \mathrm{C}\right)$ to inhibit leaching from Aluminum cook wares in solutions containing vegetables or meat. Aluminum cook wares were bought from the market from four countries and cut to make the Aluminum samples. Six types of vegetables and three kinds of meat were chosen. Each type of vegetable and meat was used to prepare $30 \% \mathrm{w} / \mathrm{v}$ aqueous solutions. Three methods were used in the present study: Gravimetric method, Atomic Absorption and FTIR. Gravimetric method was applied to determine the leaching rate and the corrosion inhibition efficiency with/without $\mathrm{NaCl}$. The effect of Curcumin concentration, Tab water, immersion time, alloying elements was investigated. There was a good consistency between Gravimetric and Atomic Absorption methods. The adsorption of Curcumin on the aluminum surface was in accordance with Langmuir isotherm. The values of the adsorption constant $\left(K_{a d s}\right)$ and the free energy of adsorption $\left(\Delta G_{a d s}^{0}\right)$ were calculated and discussed. FTIR spectrum indicated that Curcumin coordinated with $\mathrm{Al}^{3+}$ resulting in the formation of $\mathrm{Al}^{3+}$-Curcumin complex on the metal surface. Using a small amount of Curcumin decreased leaching from Aluminum cook wares into food by $60 \%-80 \%$ depending about the type of food.
\end{abstract}

\section{Keywords}

Aluminum Leaching, Curcumin, Vegetables, Meat, Gravimetric Method, Adsorption Isotherm, Atomic Absorption Method, FTIR

\section{Introduction}

Aluminum (Al) has been regarded as a neurotoxin agent since 1980 and it was associated with various disorders

How to cite this paper: Al Juhaiman, L.A. (2016) Curcumin Extract as a Green Inhibitor of Leaching from Aluminum Cookware at Quasi-Cooking Conditions. Green and Sustainable Chemistry, 6, 57-70. http://dx.doi.org/10.4236/gsc.2016.62005 
(dialysis encephalopathy and bone disorder) due to its accumulation in the brain, bones, and liver [1]-[3]. The old Provisional Tolerance Weekly Intake (PTWI) of Al from WHO/FDA in 1989 was 7 mg/Kg body weight. In 2007, the PTWI was changed to $1 \mathrm{mg} / \mathrm{Kg}$ body weight [4] which reflected the neurotoxic potential of Al. There are many sources of $\mathrm{Al}$ entering the human body which includes water, food, beverages, medicines, food additives and leaching from $\mathrm{Al}$ cookware. Many studies have been conducted on the leaching of $\mathrm{Al}$ into food or drinks and the quantitative $\mathrm{Al}$ leaching [5] and risk assessment of $\mathrm{Al}$ [6]-[10]. In these studies, the extent of $\mathrm{Al}$ leaching was strongly related to several factors such as $\mathrm{pH}$, cooking medium and composition of food. Although there is no consensus on the safety of using Al cookware, many studies do not recommend using them and regard using $\mathrm{Al}$ cook ware as hazardous.

Corrosion inhibitors are added to reduce metal leaching into solutions. The inhibitors may affect the metal leaching in two ways 1) by decreasing the available reaction area (geometric blocking effect); 2) by modifying the activation energy of the cathodic and/or the anodic reactions occurring during the inhibited corrosion process [11]. The formation of a barrier layer of the inhibitor that covers either the corrosion site or the entire surface will limit the permeability of electrolytes and water, thereby reducing the rate of metal leaching (corrosion). It is generally accepted that the organic molecules inhibit corrosion by adsorption at the metal solution interface [11] [12].

The use of turmeric dates back about 4000 years to the Vedic culture in India [13]. Curcumin (Cur) belongs to the genus Curcuma, which consists of several plant species with underground rhizomes and roots [13]. Turmeric and ginger rhizomes plants belong to the Zingiberaceae family. Curcumin (or Turmeric) was isolated as early as 1815. Curcumin $\mathrm{C}_{21} \mathrm{H}_{20} \mathrm{O}_{6}(\mathrm{MW}=368.38)$ is the principal Curcuminoid of the popular spices of India. These Curuminoids are natural phenols which are responsible for the yellow color of turmeric. Curor diferuloylmethane, (1,7-bis(4-hydroxy-3-methoxy phenyl)-1,6-heptadiene-3,5-dione) can exist in several tautomeric forms, including a 1,3-diketo form and two equivalent enol forms as shown in Figure 1. The enol form is more energetically stable in the solid phase and in solution (up to 95 percent are in the enol form) [14]. Cur is a major functional component constituting $2 \%-5 \%$ of turmeric recognized as being responsible for most of its therapeutic effects. Cur has a bright yellow color; its E number is E100. It is reported that Cur had a number of pharmacological activities including antioxidant, anticancer, anti-inflammatory, and analgesic, etc. [14]. Cur is obtained by solvent extraction of turmeric and purification of the extract by crystallization. Cur is an oil soluble pigment; it is insoluble in water at acidic and neutral $\mathrm{pH}$ but soluble in alkali. Although Cur is stable at high temperatures, it is unstable in alkaline conditions and in the presence of light [14]. The acceptable use levels of Curcumin from FAO are in the range of $5-500 \mathrm{mg} / \mathrm{kg}$ depending on the food category [15].<smiles>COc1cc(/C=C/C(=O)/C=C(O)/C=C/c2ccc(O)c(OC)c2)ccc1O</smiles>

(a)

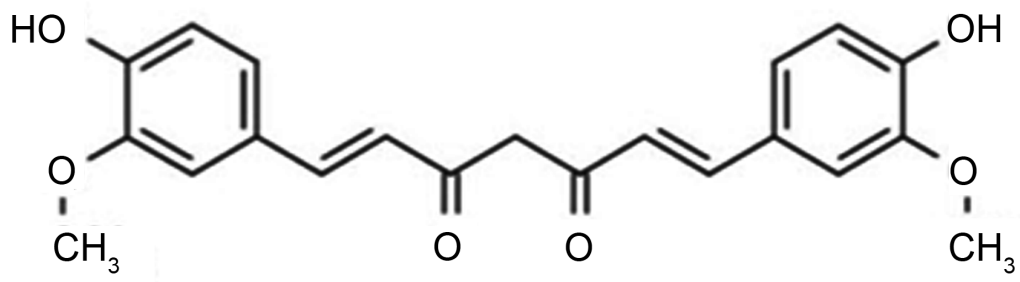

(b)

Figure 1. The molecular structure of Curcumin in nature. It can in two tautomeric forms: (a) the enol form and (b) the keto form. 
Cur was successfully used as green corrosion inhibitors for many metals [16]-[22]. Cur was used as a green corrosion inhibitor in $\alpha$-Brass [16], an inhibitor of aluminum [17] and an inhibitor of commercial $\mathrm{Al}$ in simulated concrete pore solution [18]. Moreover, corrosion inhibition of C-steel and steel by an aqueous extract of Cur was shown to be effective [19]-[22]. Cur has poor solubility in water at neutral $\mathrm{pH}$ due to a strong hydrophobicity of the conjugated alkene chain [23]. The unavailability of a strong polar group renders the molecule insoluble or sparingly soluble in polar solvents. However, in slightly acidic media, it is likely to exist in the keto form which appears to favor H-atom transfer reactions [24] [25]. The only problem for Curcumin Detection is its poor aqueous solubility although it dissolves in alcohols. A simple, reliable, accurate and reproducible study using UV-Visible Spectrophotometric method has been developed by Sharma et al. for the determination of Curcumin [26].

In many countries, especially Asia, the use of $\mathrm{Al}$ cook wares is very common due to their low prices, as many people cannot afford the cost of Pyrex or stainless steel. Thus, aim of this work is to investigate Cur aqueous extract as a green corrosion inhibitor of $\mathrm{Al}$ leaching from $\mathrm{Al}$ cookware at quasi-cooking conditions $\left(90^{\circ} \mathrm{C}\right)$ in different vegetable and meat solutions using gravimetric, atomic absorption and FTIR methods. The other electrochemical technique was not possible due to the high temperature used. The experiments were conducted in aqueous solutions to imitate real cooking conditions.

\section{Experimental Section}

All experiments were made in a lab where the amount of dust was kept to a minimum so that the $\mathrm{Al}$ constituents in dust will not affect the results. All glass wares were first cleaned in conc. $\mathrm{HNO}_{3}$ before any experiment to dissolve any residual Al.

\subsection{Materials}

1) The Al cook wares were bought from the local market from four countries China, India, Saudi Arabia and Syria. The percentage of $\mathrm{Al}$ and the alloying elements was determined in a previous study as shown in Table 1. [10]. The Al cook wares were cut into rectangular samples of dimensions about $2 \times 2.5 \mathrm{~cm}$ and $0.13 \mathrm{~cm}$ thickness. The Al samples have very small round holes to hang them with a plastic thread. The average exposed area ranged from $11-11.3 \pm 0.20 \mathrm{~cm}^{2}$. These Al samples were treated in the following method prior to each experiment. Wet polishing with emery papers up to 1000 grade, washing with distilled water, then ultrasonic cleaning in acetone (ultrasonic cleaner from Cole Palmer) for 2 min before drying. After each experiment the $\mathrm{Al}$ samples

\begin{tabular}{|c|c|c|c|c|}
\hline Alloy & China & India & Saudi & Syria \\
\hline$\% \mathrm{Al}$ & 97.902 & 98.335 & 98.583 & 98.348 \\
\hline $\mathrm{Cr}$ & 0.030 & 0.021 & 0.041 & 0.061 \\
\hline $\mathrm{Cu}$ & 0.069 & 0.352 & 0.380 & 0.147 \\
\hline $\mathrm{Fe}$ & 0.522 & 0.206 & 0.103 & 0.223 \\
\hline $\mathrm{Ga}$ & 0.018 & 0.014 & 0.012 & 0.013 \\
\hline $\mathrm{Mn}$ & 0.351 & 0.080 & 0.190 & 0. 230 \\
\hline Mo & 0.272 & 0.109 & 0.123 & 0.112 \\
\hline $\mathrm{Mg}$ & 0.162 & 0.322 & 0.171 & 0.120 \\
\hline Sn & 0.401 & 0.213 & 0.122 & 0.260 \\
\hline $\mathrm{Pb}$ & 0.030 & 0.051 & 0.070 & 0.015 \\
\hline $\mathrm{Si}$ & 0.062 & 0.099 & 0.097 & 0.182 \\
\hline Se & --- & 0.018 & 0.070 & --- \\
\hline $\mathrm{Ti}$ & 0.050 & 0.040 & --- & 0.012 \\
\hline $\mathrm{Zn}$ & 0.131 & 0.140 & 0.038 & 0.077 \\
\hline
\end{tabular}


were soaked in a cleaning solution containing methanol to dissolve the Cur layer adsorbed on $\mathrm{Al}$ surface.

2) Six kinds of vegetables (Carrot, Onion, Green Beans (G. Beans), Potato, Tomato and Zucchini) were washed and cut into small pieces except green beans which were used whole. Potatoes and onions were peeled. Thirty grams of each vegetable (30.0 $\pm 0.02 \mathrm{~g}$ ) was used to prepare $30 \% \mathrm{w} / \mathrm{v}$ vegetable solutions using a sensitive balance (Mettler Toledo balance $\pm 0.00001 \mathrm{~g}$ ).

3) Three kinds of ground meat, lamb (from the thigh), chicken (from the breast), and fish (Hamour fillet), were used.

Cur (98\%) was purchased from Acros Organics Company, USA. One gram of pure Cur was dissolved in 700 $\mathrm{mL}$ of distilled water, heated to $90^{\circ} \mathrm{C}$, and filtered using Sigma-Aldrich sintered glass funnel No. 3 (pore size16 $40 \mu \mathrm{m})$. The precipitate was washed with additional amounts of hot distilled water then the Cur extract was cooled, transferred to a volumetric flask and then diluted to $1000 \mathrm{~mL}$. Due to the discrepancy in reporting Curcumin aqueous solubility, the solubility of the Cur sample was determined as follows. The remaining solid precipitate of Curcumin was dissolved from the sintered glass funnel with methanol into a beaker with known weight. Then the methanol was evaporated and the remaining dry solid precipitate was weighed and subtracted from the original weight $(1 \mathrm{~g})$. A certain volume of the stock Cur solution was added to $30 \mathrm{~g}$ of the vegetable OR meat solutions to make the final concentration 20 - 100 ppm of Cure extract. Commercial Cur from an Indian company was bought from the local market. It was prepared by adding $0.10 \mathrm{~g}$ from Cur to $30 \mathrm{~g}$ of the vegetable OR meat then adjusting the volume to $100 \mathrm{~mL}$ to make $0.10 \% \mathrm{w} / \mathrm{w}$ solution. The solubility of Cur is known to be about $0.1 \mathrm{mg} / \mathrm{mL}$ for many Cur product sold in the net. This result is different from the Cur solubility reported by Kurien et al. [23] as $0.6 \mu \mathrm{g} / \mathrm{mL}$ which seemed unreasonable. For Jagannathan et al. [25], the solubility of Cur was reported as $2 \mathrm{mg}$ in $3 \mathrm{~mL}(0.666 \mathrm{mg} / \mathrm{mL})$. Due to the discrepancy in reporting Curcumin aqueous solubility, the solubility of the Cur sample from Acros was experimentally determined in the present study. The aqueous solubility of Curcumin extract was determined to be $0.150 \mathrm{mg} / \mathrm{mL}$. Taking into account the purity of Cur solid (98\%), the prepared Cur extract stock solution was calculated as $0.147 \mathrm{mg} / \mathrm{mL}$. This solution was stable for about one month in the dark. According to Jagannathan et al. [25], the formation of intermolecular aggregates may be responsible for the stability of Cur at room temperature after cooling the hot aqueous suspension.

4) $\mathrm{NaCl}$ (AR from Merck) was used in a small concentration $(0.50 \mathrm{~g} \mathrm{NaCl}$ in $100 \mathrm{~mL}$ of the test solution) to imitate the cooking conditions.

Methanol from BDH of purity (99.5\%) was used to clean the $\mathrm{Al}$ samples.

\subsection{Experimental Methods}

\subsubsection{Gravimetric Method (Weight Loss)}

In the present study, weight loss method (WL) at $90^{\circ} \mathrm{C}$ is used to study $\mathrm{Al}$ leaching due to $30 \% \mathrm{w} / \mathrm{v}$ vegetable OR meat solutions in the presence and absence of Cur to simulate cooking conditions. A certain amount of Cur solution was added to $30 \%$ of the test solutions w/without $\mathrm{NaCl}$ to obtain the final Cur concentration of 20 - 100 $\mathrm{ppm}$. The test solution (Sol.) was introduced to the water bath to acquire the desired temperature. Then the Al sample was hanged in the test solution and heated at $90^{\circ} \mathrm{C}$ for one hour. After WL method, the $\mathrm{Al}$ samples were cleaned in ultrasonic bath for 2 minutes in methanol to remove the adsorbed Cur layer. This procedure was not enough as there was an increase in the weight. Thus the $\mathrm{Al}$ samples were immersed in a cleaning solution (5\% $\mathrm{H}_{3} \mathrm{PO}_{4}+2 \% \mathrm{CrO}_{3}$ ), at $80^{\circ} \mathrm{C}$ for 10 minutes to remove the reaction products from the $\mathrm{Al}$ surface. Finally, it was washed with distilled water (DW) and then acetone. The dry Al sample was weighed again to determine the weight loss, in a sensitive balance.

\subsubsection{Atomic Absorption Method (AA)}

The remaining test solutions after WL experiments were analyzed to determine the amount of dissolved $\mathrm{A}^{3+}$ using Atomic absorption method (Agilent Technologies-200 series AA, double beam). One $\mathrm{mL}$ of the remaining Sol. was diluted to $10 \mathrm{~mL}$ by standard $\mathrm{KCl}$ solution. The calibration curve was prepared using standard $\mathrm{Al}$ solutions in the concentration range 5 - $25 \mathrm{ppm}$. All standard $\mathrm{Al}$ solutions were diluted with $\mathrm{KCl}$ solution. A mean of two to three experiments were reported.

\subsubsection{FTIR}

FTIR spectra were recorded in the solid state (KBr pellets) in the range $600-4000 \mathrm{~cm}^{-1}$ using a Perkin Elmer- 
Spectrum BX spectrophotometer.

\section{Results and Discussion}

\subsection{Gravimetric Measurements}

In a previous study [9] [10], the extract of these six vegetable and meat solutions were shown to cause leaching of Al cookware. In the present study, the vegetables were used in small pieces to imitate real cooking conditions. The $\mathrm{Al}$ leaching was calculated from the Corrosion rate (CR) using the following equation:

$$
\mathrm{CR}=\frac{\Delta W}{A \times t}
$$

The weight loss of $\mathrm{Al}$ alloy is $\Delta w$; it is calculated by subtracting the $\mathrm{Al}$ sample's original weight from the sample's weight after immersion in the test solution (mg). The exposed surface area of Al sample $\left(\mathrm{cm}^{2}\right)$ is $A$; and $t$ is the immersion time (one hour). The inhibition efficiency (\%IE) and surface coverage $(\theta)$ are calculated from the following equations:

$$
\begin{gathered}
\theta=\left(1-\frac{\mathrm{CR}}{\mathrm{CR}^{0}}\right) \\
\% \mathrm{IE}=\theta \times 100
\end{gathered}
$$

$\mathrm{CR}$ and $\mathrm{CR}^{0}$ are the corrosion rates in the absence and presence of Cur respectively.

An average of two to three similar experiments was reported where the difference is within $5 \%-7 \%$.

\subsubsection{Effect of Cur on Al Leaching in Vegetable and Meat Solutions w/without NaCl}

To test the effect of a certain inhibitor concentration, an amount of Cur was added to $30 \%$ vegetable solutions with/without $\mathrm{NaCl}$ in distilled water $(100 \mathrm{~mL})$ to make the final Cur concentration equal $60 \mathrm{ppm}$. The addition of Cur reduced the Al leaching to different extents as shown in Table 2. The inhibition efficiency in the presence of $\mathrm{NaCl}$ was lower than in its absence due to the aggressive effect of chloride ion which agrees with many studies [7] [19] [27]. It is shown in Table 2, that there is a difference in Al leaching depending on the composition of vegetable solutions which is in agreement with other studies that adding more anions which form different complexes with $\mathrm{Al}^{3+}$ in the test solutions increases the Al leaching [7] [8] [10] [28]-[30]. It is noticed that using the vegetable pieces instead of the vegetable extract gave lower CR values by about $11 \%$ [10]. The $\mathrm{pH}$ of $30 \%$ vegetable solutions ranged between 4.5 for Tomato to 6.4 for Potato. Al exhibits a passive behavior in aqueous solutions due to the protective compact $\mathrm{Al}_{2} \mathrm{O}_{3}$ film on its surface. However, the solubility of this protective film increases in acidic and alkaline medium. Solution $\mathrm{pH}$ normally influences the leaching behaviour of $\mathrm{Al}$ and its alloys by changing the solubility of the $\mathrm{Al}$ oxide film. Accordingly, the difference in corrosion rate from WL for Al in the test solutions is attributed to the change in the solubility of the oxide film. In neutral solutions, this protective film has low solubility hence the lowest corrosion rate was observed in such solutions (Carrot and Potato). However, at low $\mathrm{pH}$ the solubility of the $\mathrm{Al}$ oxide layer is enhanced which leads to higher corrosion rates as shown for Tomato, G. Beans and Zucchini. It is known that tomato and acidic vegetables contain a high percentage of citric acid which explains their low pHs. It was well established that cooking acidic foods in Al utensils causes high leaching of Al into the food [8] [10] [28]. The \% IE was calculated in 30\% vegetable solution. The \% IE ranged between $67.1 \%$ for onion solution to $86.8 \%$ for tomato solution and decreased slightly after adding $\mathrm{NaCl}$ as shown in Table 2 . The same procedure was performed in the presence of $30 \%$ meat solutions w/without $\mathrm{NaCl}$ in the presence of $60 \mathrm{ppm}$ Cur as shown in Table 2. The \% IE was between 77\% $80 \%$. The highest $\mathrm{Al}$ leaching was found with $30 \%$ fish solution and the lowest leaching was found with chicken which agrees with a previous study [9].

Calculating the solubility of the commercial Cur was $0.106 \mathrm{mg} / \mathrm{mL}$ which is lower than the solubility of 0.15 $\mathrm{mg} / \mathrm{mL}$ for the Acros Cur. There were a lot of fibres in the commercial Cur residue. Moreover, the same previous procedure was repeated using 0.10 grams of Cur in $100 \mathrm{~mL}$ solution $(1000 \mathrm{ppm})$. The results are shown in Table 3. The addition of $0.10 \mathrm{~g}$ of Cur powder to the Onion and Potato solution showed the lowest \% IE. Surprisingly, the \% IE was lower than the pure Cur although the concentration of the commercial Cur was much higher than that of the pure Cur. The concentration of Cur is lower in solution which explains the lower IE compared to the pure Acros Cur. 
Table 2. CR and IE of $\mathrm{Al}$ after immersion for 1 hour at $90^{\circ} \mathrm{C}$ in $30 \%$ vegetable or meat solutions (Sol.) w/without $60 \mathrm{ppm}$ Cur using the Indian $\mathrm{Al}$ samples.

\begin{tabular}{|c|c|c|c|c|}
\hline & \multirow{2}{*}{$\begin{array}{c}\mathrm{CR} \times 10^{2}\left(\mathrm{mg} / \mathrm{cm}^{2} \cdot \mathrm{hr}\right) \\
\text { Sol. }\end{array}$} & \multirow{2}{*}{ \% IE (Sol. + Cur) } & \multirow{2}{*}{$\begin{array}{c}\mathrm{CR} \times 10^{2}\left(\mathrm{mg} / \mathrm{cm}^{2} \cdot \mathrm{hr}\right) \\
\text { Sol. }+\mathrm{Cl}\end{array}$} & \multirow{2}{*}{$\%$ IE $($ Sol. + Cur + Cl) } \\
\hline & & & & \\
\hline Carrot & 2.78 & 73.8 & 3.02 & 69.6 \\
\hline G. Beans & 3.81 & 84.3 & 4.01 & 80.3 \\
\hline Onion & 2.93 & 67.1 & 3.05 & 62.9 \\
\hline Potato & 1.69 & 71.5 & 1.88 & 70.1 \\
\hline Tomato & 5.07 & 86.8 & 5.42 & 77.2 \\
\hline Zucchini & 4.98 & 81.4 & 5.28 & 80.7 \\
\hline Lamb & 3.08 & 80.8 & 3.45 & 77.2 \\
\hline Chicken & 2.21 & 81.2 & 2.91 & 78.3 \\
\hline Fish & 4.85 & 79.9 & 5.32 & 79.1 \\
\hline
\end{tabular}

Table 3. Mean CR and IE of $\mathrm{Al}$ after immersion for 1 hour at $90^{\circ} \mathrm{C}$ in $30 \%$ vegetable or meat solutions (S) w/without $0.10 \mathrm{~g}$ of a local Cur using the Indian $\mathrm{Al}$ samples.

\begin{tabular}{ccc}
\hline & $\mathrm{CR} \times 10^{2}\left(\mathrm{mg} / \mathrm{cm}^{2} \cdot \mathrm{hr}\right)$ & \% IE (Sol. + Cur) \\
\cline { 2 - 3 } Carrot & Sol. & 57.7 \\
G. Beans & 2.78 & 74.3 \\
Onion & 3.81 & 44.6 \\
Potato & 2.93 & 33.9 \\
Tomato & 1.69 & 74.9 \\
Zucchini & 5.07 & 68.1 \\
Lamb & 4.98 & 71.5 \\
Chicken & 3.08 & 74.7 \\
Fish & 2.21 & 76.3 \\
\hline
\end{tabular}

\subsubsection{Effect of Cur Concentration on Al Leaching in Zucchini Solutions w/without $\mathrm{NaCl}$}

To test the effect of inhibitor concentration, 20 - $100 \mathrm{ppm}$ of Cur was added to a solution containing 30\% w/w Zucchini w/without $\mathrm{NaCl}$ at $90^{\circ} \mathrm{C}$. The results are shown in Table 4 . The \% IE increased with increasing Cur concentration to reach its highest inhibition of $94.4 \%$ without $\mathrm{NaCl}$ and $90.1 \%$ with $\mathrm{NaCl}$ at 100 ppm Cur. The \% IE for $\mathrm{Al}$ is slightly higher in the absence of $\mathrm{NaCl}$ than in its presence which is due to the corrosive effect of chloride ions. The \% IE increased with increasing Cur concentration in the range of $0.543-2.715 \times 10^{-4} \mathrm{M}$. This trend agrees with Elmsellem et al. [22] using Cur as inhibitor for mild steel in $1.0 \mathrm{M} \mathrm{HCl}$ solution in the concentration range $10^{-6} \mathrm{M}$ to $10^{-3} \mathrm{M}$.

Curcumin suffers from two major difficulties. The first one is the instability of this molecule as it is highly degradable at ambient condition [25]. The Cur solution stability was one month at ambient temperatures [25]. The second difficulty is its very low solubility in water that led Jagannathan et al. [25] to report that it is more accurate to say that Cur disperses rather than dissolve in water. It was difficult to compare the results from the present study with the other studies because of the inconsistency in the preparation of Cur solutions and the discrepancy in taking into accounts the Cur solubility in most studies. For example, the other studies prepared the Cur solutions as:

1) Fouda \& Eletter [16] used Cur in pyridine solvent.

2) Abdul Halim et al. [17] prepared 10 - 60 g/L solutions.

3) For Rajendran et al. [18] and Johnserani et al. [19], they boiled $10 \mathrm{~g}$ of rhizome (Curcuma longa L.) powder 
Table 4. The change of $\%$ IE, $\theta$ with different concentration of Cur from WL after immersion for 1 hour at $90^{\circ} \mathrm{C}$ in $30 \%$ w/v Zuc solution.

\begin{tabular}{cccc}
\hline $\begin{array}{c}\text { Cur } \\
(\mathrm{ppm})\end{array}$ & $\begin{array}{c}\text { Cur } \\
(\mathrm{mol} / \mathrm{L})\end{array}$ & $\begin{array}{c}\theta \\
\text { Zuc only }\end{array}$ & $\begin{array}{c}\theta \\
\text { Zuc }+\mathrm{NaCl}\end{array}$ \\
\hline 20 & $0.543 \times 10^{-4}$ & 0.640 & 0.610 \\
40 & $1.086 \times 10^{-4}$ & 0.703 & 0.647 \\
60 & $1.629 \times 10^{-4}$ & 0.814 & 0.762 \\
80 & $2.172 \times 10^{-4}$ & 0.873 & 0.812 \\
100 & $2.715 \times 10^{-4}$ & 0.944 & 0.901 \\
\hline
\end{tabular}

with double distilled water, filtered to remove suspended impurities and made the solution up to $100 \mathrm{~mL}$.

4) For Al-Fakeh et al. [20], the concentration range of Curcumin inhibitor employed was 2.5 - $10 \mathrm{~g} / \mathrm{L}$.

5) Nasibi et al. [21] prepared Cur solutions using $0.030 \mathrm{~g} / \mathrm{L}(30 \mathrm{mg} / \mathrm{mL})$.

6) For Elmsellem et al. [22], Curcumin of 98\% were obtained from ACROS ORGANICS and the concentration range of Curcumin inhibitor employed was $10^{-6}-10^{-3} \mathrm{M}$ (equivalent to $368-0.368 \mathrm{mg} / \mathrm{L}$ ).

7) Sneharani et al. [24] prepared $30 \mathrm{nM}$ (equivalent to $0.011 \mathrm{mg} / \mathrm{L}$ ).

The two studies that are close to the concentration of the present study are Nasibi et al. [21] and Elmsellem et al. [22]. Regardless of the preparation method of the Cur test solutions, all studies which used Cur as corrosion inhibitors agree that the corrosion inhibition efficiency of the metal increased with increasing cur concentration [16]-[22].

\subsection{Atomic Absorption Method (AA)}

The solutions after WL method were used for the Atomic absorption (AA) experiments. Using AA for analysis after WL method is not a common method in the literature although BÖRÖCZ-SZABó [31] had found similar correlation between the two methods for stainless steel in 1977 [31]. This application was confirmed by other studies as well [10] [27].

\subsubsection{Effect of Concentration by AA Method}

To be sure that the amount of $\mathrm{Al}^{3+}$ detected by AA comes only from $\mathrm{Al}$ cookware leaching using the Indian alloy, AA experiments were done for the DW used and the blank vegetable solutions. The concentrations of $\mathrm{Al}^{3+}$ were below the detection limit of the instruments (ppm range). Thus the concentrations of $\mathrm{Al}^{3+}$ calculated for the test solutions are due to $\mathrm{Al}$ leaching from $\mathrm{Al}$ cook wares only. The analysis of the $\mathrm{Al}^{3+}$ ions dissolved in the test solutions by AA are calculated in $\mathrm{ppm}(\mathrm{mg} / \mathrm{L})$ using a standard $\mathrm{Al}$ solution. To compare the AA results with the WL data, the results from AA were multiplied by the appropriate dilution factor then they were divided by the area of $\mathrm{Al}$ sample used. As an example, $30 \% \mathrm{w} / \mathrm{v}$ of the vegetable solutions were analysed by AA. The results of WL and AA are shown in Figure 2. A good consistency was observed between the data from WL and AA with WL being lower in all solutions as the extent of detection of AA is in the ppm range.

\subsubsection{Effect of Tab Water by AA Method}

The effect of using Tab water was studied for 30\% w/v Zuc only and $60 \mathrm{ppm}$ Cur w/without NaCl. The results are shown in Figure 3. The Al leaching is found to be higher by about $14.3 \%$ after adding $\mathrm{NaCl}$ to Tab $\mathrm{W}$ and DW. The corrosive effect of $\mathrm{NaCl}$ is proved by many studies [25]-[30]. The $\mathrm{Al}$ leaching in $30 \% \mathrm{w} / \mathrm{v} \mathrm{Zuc}$ in Tab water is slightly higher than $\mathrm{Al}$ leaching in DW. This is a probable result of the presence of other soluble anions in Tab W which increases the Al leaching [5] [10]. The inhibition effect of Cur is comparable in DW and Tab water w/without $\mathrm{NaCl}$.

\subsubsection{Effect of Immersion Time by AA Method}

The effect of immersion time was investigated at 30, 45 and 60 minutes for 30\% Zuc w/without $60 \mathrm{ppm}$ Cur at $90^{\circ} \mathrm{C}$. The results are shown in Figure 4. The amount of $\mathrm{Al}$ leaching increased with time for Zuc. The amount of $\mathrm{Al}$ leaching for Zuc + Cur decreased after 30 minutes and did not change much after 60 minutes. These results indicate that Cur Inhibitor is adsorbed mostly at the earlier stages. 


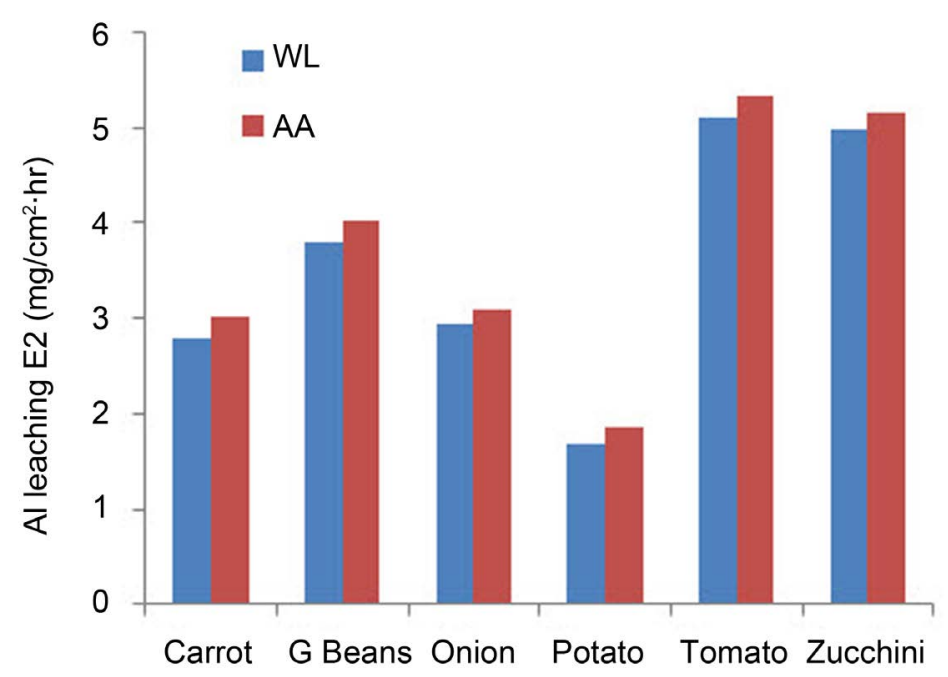

Figure 2. Comparison of $\mathrm{Al}$ leaching from AA and WL for 30\% vegetable solutions.

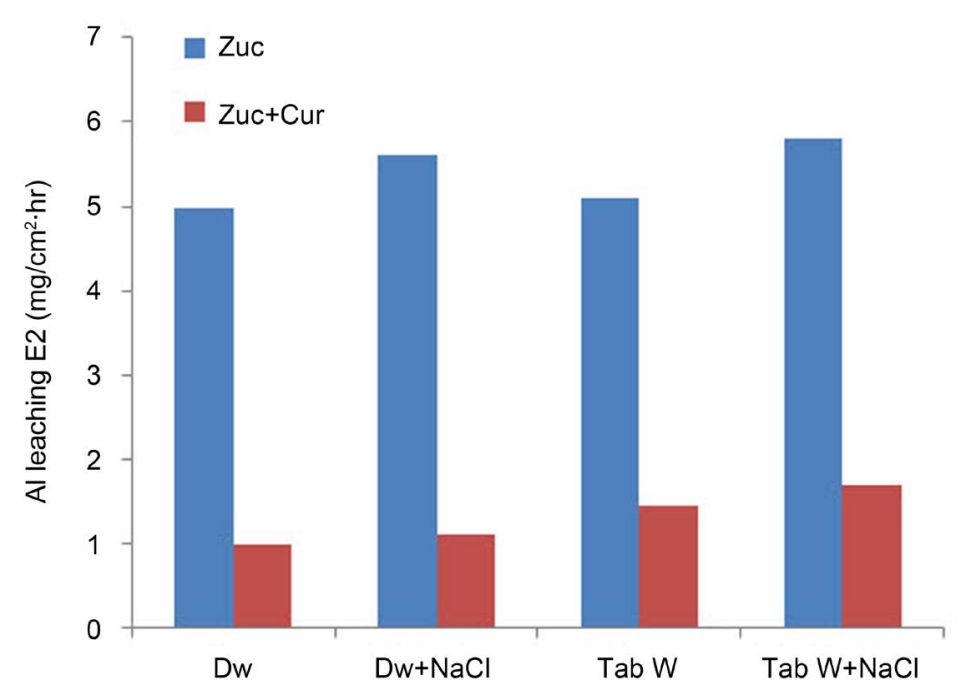

Figure 3. Effect of Tab water and DW on Al leaching for 30\% Zuc and 60 ppm Cur with/without $\mathrm{NaCl}$.

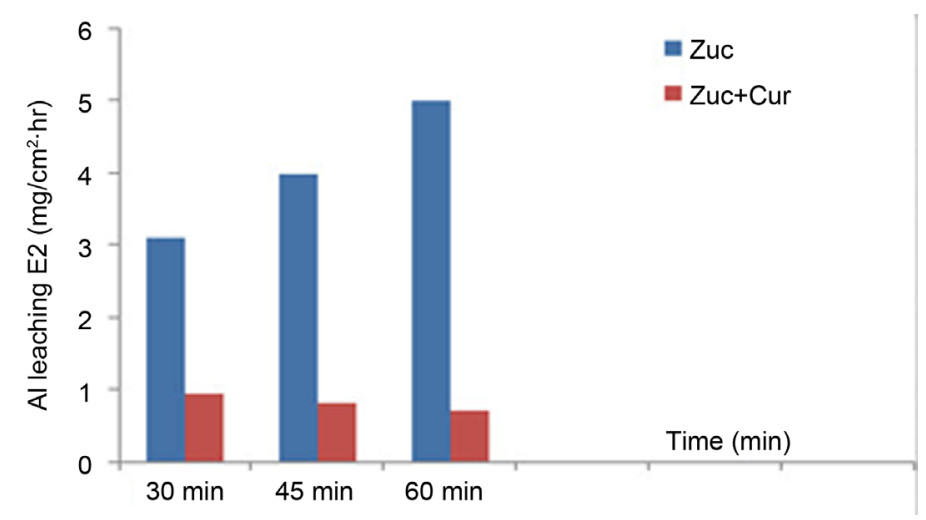

Figure 4. Effect of immersion time on $\mathrm{Al}$ leaching for $30 \% \mathrm{Zuc}$ w/without $60 \mathrm{ppm}$ Cur at $90^{\circ} \mathrm{C}$. 


\subsubsection{The Effect of Alloying Elements}

To test the effect of alloying elements, the amount of $60 \mathrm{ppm}$ Cur was added to 30\% w/v zucchini (Zuc) in distilled water using the four kinds of Al cookware from China, India, Saudi Arabia and Syria as shown in Figure 5. The Indian alloy showed the highest $\mathrm{Al}$ leaching. The percentage of $\mathrm{Mg}(0.33 \%)$ and $\mathrm{Zn}(0.14 \%)$ which are known to increase Al dissolution are higher in the Indian alloy compared to the others [5] [10]. Chromium and copper are known to reduce the corrosion rate [11]. This alloying elements' effect cannot be attributed to the absence of a single alloying element or the presence of another but rather to the total synergistic effect of all the alloying elements. Although the Indian alloy showed the highest Al leaching, the addition of $60 \mathrm{ppm}$ Cur reduced the $\mathrm{Al}$ leaching to an extent which resembles that from other countries. Finally, these $\mathrm{Al}$ cook wares may represent one factory only but at least it gives indication about the effect of alloying elements in $\mathrm{Al}$ leaching.

\subsection{Fourier Transform Infra-Red Analysis (FTIR)}

The FTIR spectrum of the protective film formed on the surface of the metal after immersion in the test solution containing the Curcumin extract was dissolved in methanol. The FTIR spectrum of Cur in methanol is also shown in Figure 6. The FTIR spectrum data of Curcumin in methanol is explained in Table 5. The most prominent change was in the following vibrations:

The C-O-C asymmetrical stretching frequency of aryl alkyl ethers, the mixed vibrations of $v(\mathrm{C}=\mathrm{O}), \delta(\mathrm{CCC})$, and $\delta(\mathrm{CC}=\mathrm{O})$ aromatic $v(\mathrm{CC}), v(\mathrm{CCH})$ and the $\mathrm{C}=\mathrm{O}$ stretching frequency.

It may be inferred from FTIR spectrum Figure 6 that Cur has coordinated with $\mathrm{Al}^{3+}$ through the phenolic oxygen, ethereal oxygen, and carbonyl oxygen, resulting in the formation of the $\mathrm{Al}^{3+}$-Curcumin complex on the anodic sites of the metal surface. Our findings agree with Johnsirani et al. [19] about adsorption Curcumin extract on carbon steel in sea water [19]. The present findings is also in agreement with Elmsellem et al. [22] using quantum chemical calculations "The density distributions of the frontier molecular orbital (HOMO and LUMO) show that Curcumin adsorbs through the actives centers of oxygen and $\pi$ electrons of the Curcumin ring” [22].

Table 5. FTIR spectrum data of Curcumin and its complexes of $\mathrm{Al}$ in methanol.

\begin{tabular}{|c|c|c|}
\hline Assigned peak & Cur & Cur-Al \\
\hline The C-O-C stretching of alkyl aryl ether stretching frequency & $1029 \mathrm{~cm}^{-1}$ & $1026 \mathrm{~cm}^{-1}$ \\
\hline The C-O-C asymmetrical stretching frequency of aryl alkyl ethers & $1226 \mathrm{~cm}^{-1}$ & Disappeared \\
\hline The mixed vibrations of $v(\mathrm{C}=\mathrm{O}), \delta(\mathrm{CCC})$, and $\delta(\mathrm{CC}=\mathrm{O})$ aromatic $v(\mathrm{CC}), v(\mathrm{CCH})$ & $1452 \mathrm{~cm}^{-1}$ & $1385 \mathrm{~cm}^{-1}$ \\
\hline The $\mathrm{C}=\mathrm{O}$ stretching frequency & $1708 \mathrm{~cm}^{-1}$ & Disappeared \\
\hline The -OH stretching frequency & $3347 \mathrm{~cm}^{-1}$ & $3345 \mathrm{~cm}^{-1}$ \\
\hline
\end{tabular}

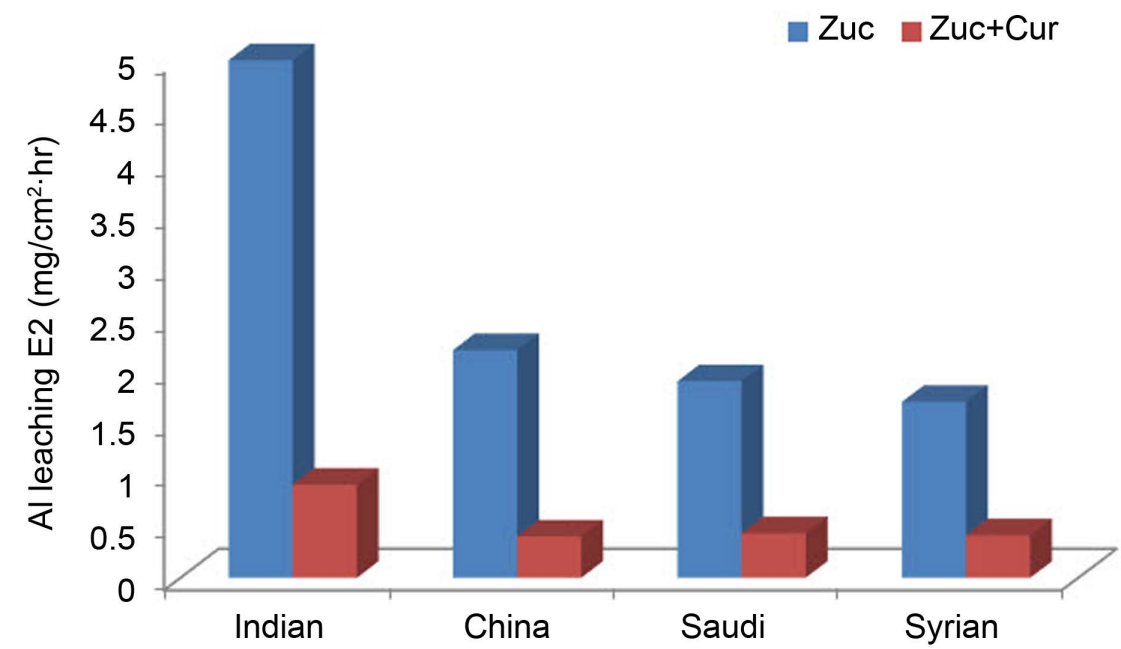

Figure 5. Effect of a alloying elements in 30\% w/v Zuc solutions and $60 \mathrm{ppm}$ Cur using the four kinds of Al cook wares. 


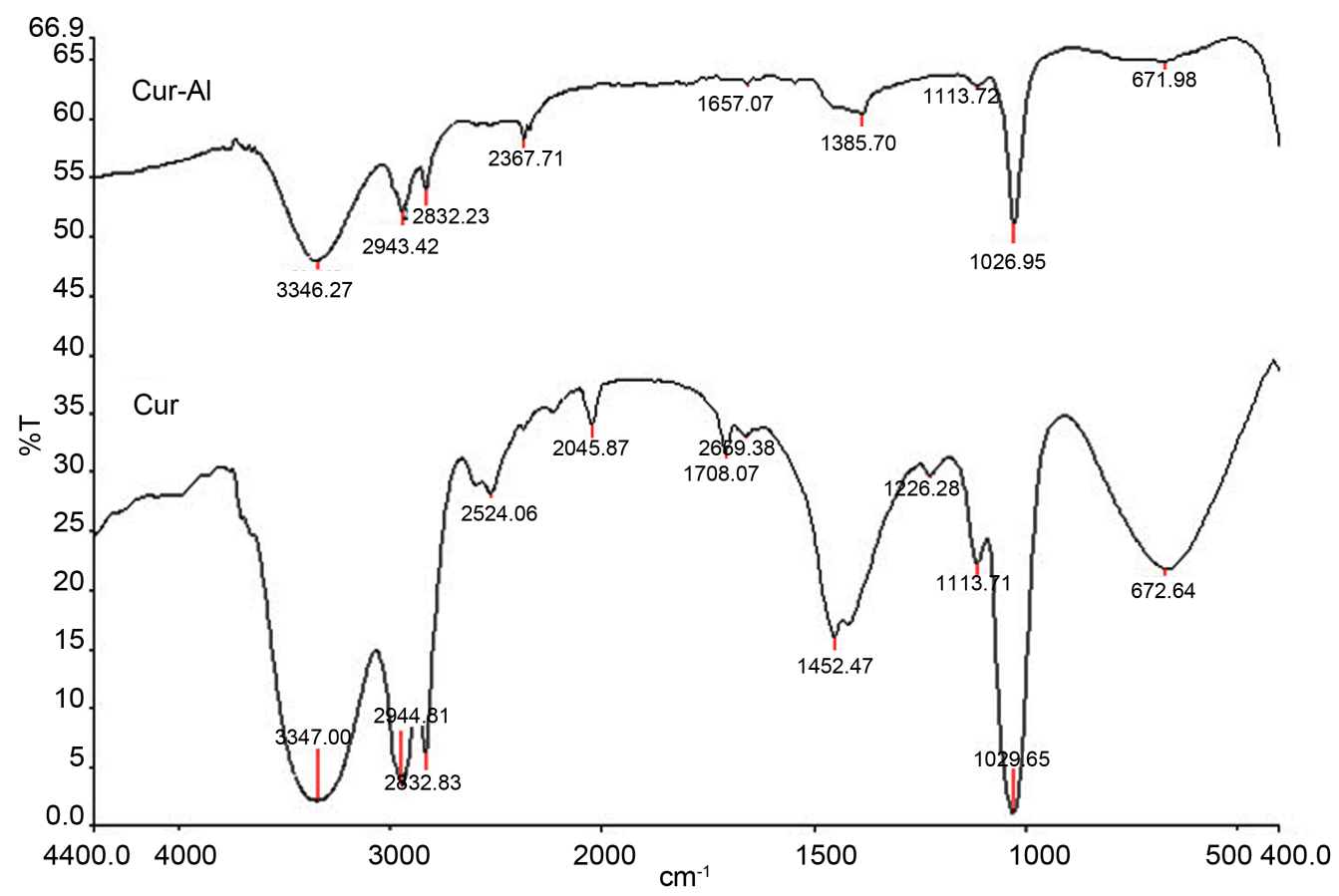

Figure 6. FTIR of Cur and Cur adsorbed on Al surface in methanol.

The present study agrees with the findings of Subhan et al. [32] who prepared Curcumin and metal complexes ( $\mathrm{M}=\mathrm{Eu}, \mathrm{Ce}, \mathrm{La}, \mathrm{Y}, \mathrm{Cr}, \mathrm{Pd})$ and characterized them by IR and UV-vis spectroscopy. Their results showed that Curcumin coordinated with metal ions in bidentate mode in deprotonated form [32]. Thus, the FTIR spectral study leads to the conclusion that the protective film consists of the $\mathrm{Al}^{3+}$-Curcumin complex.

\subsection{Adsorption Mechanism}

Different adsorption isotherms were tested in order to find the best fitted adsorption isotherm. Langmuir adsorption isotherm gave the best fit.

1) Freundlich isotherm did not fit our data.

2) Frumkin isotherms did not fit our data.

3) Temkin isotherm gave a moderate fit lower than Langmuir adsorption isotherm.

4) Langmuir adsorption isotherm gave a good fit to our data which will be shown only.

The linear Langmuir equation may be formulated as:

$$
\frac{C_{i n h}}{\theta}=\frac{1}{K_{a d s}}+C_{i n h}
$$

where $C_{i n h}$ is the concentration of inhibitor ( $\left.\mathrm{mol} / \mathrm{L}\right), \theta$ is the surface coverage and $K_{a d s}$ is the equilibrium constant of the adsorption process.

Langmuir adsorption isotherm assumes that 1 ) The metal surface contains a fixed number of adsorption sites. 2) Each site holds one adsorbate only. 3) $\Delta G$ is the same for all sites and it is independent of $\Theta$. 4) The adsorbates do not interact with one another, i.e. there is no effect of lateral interaction of the adsorbates on $\Delta G$.

The adsorption of aqueous cur on the surface of Al metal is regarded as substitution adsorption process between the Cur compound in the aqueous phase (Org) and the water molecules adsorbed on the Al surface:

$$
\mathrm{Org}_{(\mathrm{sol})}+\mathrm{X}\left(\mathrm{H}_{2} \mathrm{O}\right)_{(\text {ads })} \leftrightarrow \mathrm{Org}_{(\mathrm{ads})}+\mathrm{X}\left(\mathrm{H}_{2} \mathrm{O}\right)_{(\mathrm{sol})}
$$

where $X$ is the number of water molecules replaced by one organic molecule.

To investigate the adsorption mechanism of Cur on $\mathrm{Al}$, the data from Table 4 are used to calculate the adsorption parameters. The results are shown in Figure $7 \mathrm{w} /$ without $\mathrm{NaCl}$. A straight line relationship was obtained. 


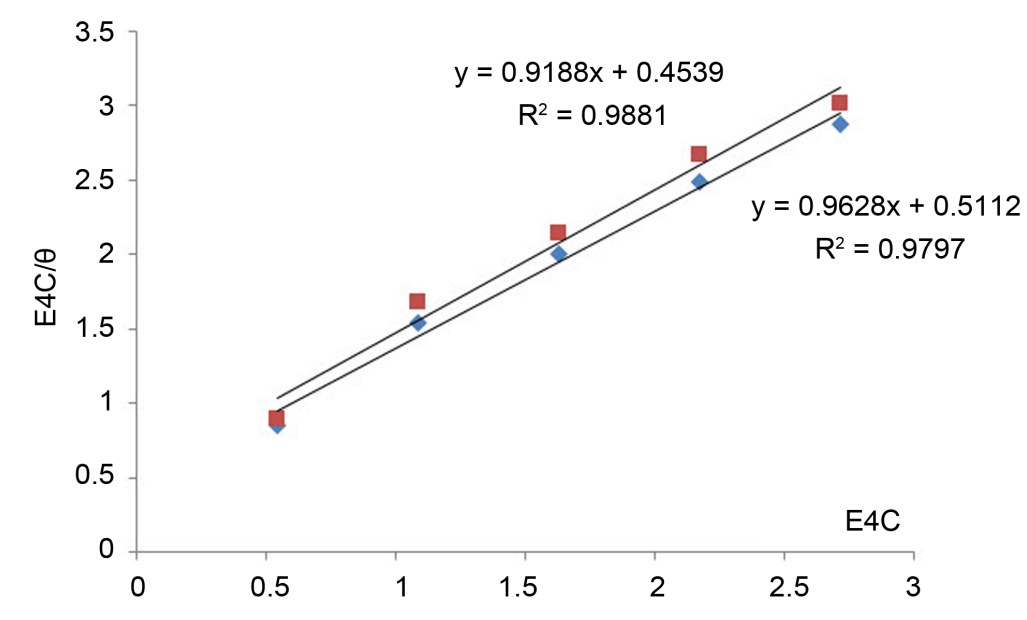

Figure 7. Plots of [C]/ $\theta$ versus [C] for $30 \% \mathrm{w} / \mathrm{v}$ Zuc Solution with/without $\mathrm{NaCl}$. Red line is Zuc + Cur, Blue line is $\mathrm{Zuc}+\mathrm{Cur}+\mathrm{NaCl}$.

Applying linear Langmuir isotherm with/without $\mathrm{NaCl}$ showed that $R^{2}=0.980$ for (Zuc only) and 0.988 for $(\mathrm{Zuc}+\mathrm{NaCl})$ with a slope about one.

The adsorption-desorption equilibrium constant $K_{a d s}$ was determined from the inverse of the intercept of the Langmuir isotherm which equals $2.203 \times 10^{4} \mathrm{~L} / \mathrm{mol}$ for Zuc and $1.956 \times 10^{4} \mathrm{~L} / \mathrm{mol}$ for Zuc $+\mathrm{NaCl}$. The free energy of adsorption ( $\Delta G_{a d s}^{0}$ ) was calculated according to the equation:

$$
\Delta G_{a d s}^{o}=-R T \ln \left(55.5 K_{a d s}\right)
$$

where 55.5 is the water concentration in mol/L, $R$ is the universal gas constant, and $T$ is the thermodynamic temperature $\left(90^{\circ} \mathrm{C}\right)$.

$$
\Delta G_{a d s}^{o}=-8.314 \times 363 \times \ln \left(2.203 \times 10^{4} \times 55.5\right)=-8.314 \times 363 \times 14.016=-42.30 \mathrm{~kJ} / \mathrm{mol} .
$$

From Figure 7, $K_{\text {ads }}$ of Cur in presence of $\mathrm{NaCl}$ was determined as $1.956 \times 10^{4} \mathrm{~L} / \mathrm{mol}$ for Zuc $+\mathrm{NaCl}$. Thus

$$
\Delta G_{\text {ads }}^{\mathrm{o}}=-41.94 \mathrm{~kJ} / \mathrm{mol} \text {. }
$$

The value of $K_{a d s}$ and $\Delta G_{a d s}^{o}$ in presence of Zuc solution is higher than their values in presence of $\mathrm{NaCl}$. The $K_{a d s}$ values may be taken as a measure of the strength of the adsorption forces between the inhibitor molecules and the metal surface [12]. Adherence to the Langmuir adsorption isotherm is generally regarded as indicating that Cur molecules are adsorbed on the surface as a single layer. The negative value of $\Delta G_{a d s}^{o}$ indicates that the adsorption process of the inhibitor is spontaneous. The value of $\Delta G_{\text {ads }}^{0}$ being of the order more than $40 \mathrm{~kJ} / \mathrm{mol}$, indicates that Cur was chemically adsorbed on $\mathrm{Al}$ surface [12]. Large $\Delta G_{\text {ads }}^{\circ}$ values imply a more efficient adsorption and hence better inhibition efficiency. This reflects a stronger adsorption in the present study. The value of $\Delta G_{a d s}^{o}$ at $363 \mathrm{~K}$ from the present study is higher than that of Kairi and Kassim [33] who got $\Delta G_{a d s}^{o}=$ $-28.82 \mathrm{~kJ} / \mathrm{mol}$ at $328 \mathrm{~K}$ in $1 \mathrm{M} \mathrm{HCl}$ solution. They found that the inhibition efficiency decreases with the rise of temperature, indicating that at higher temperature, dissolution of mild steel in $\mathrm{HCl}$ predominates on the surface [33]. Their range of concentration was 5 - 80 ppm of Cur [33]. On the other hand, the present values are different than Langmuir parameters obtained by Al-Fakih et al. [20] because they used g/L instead of the molar concentration of the inhibitor. The value of $\Delta G_{\text {ads }}^{0}$ at $363 \mathrm{~K}$ from the present study is much higher than the value of $\Delta G_{a d s}^{o}$ of $-19.35 \mathrm{~kJ}$ for $5 \%$ cinnamon inhibitor at the same temperature.

The adsorption of Cur molecules could take place via the interaction with the vacant d-orbitals of $\mathrm{Al}$ atoms (chemisorption). The ability of Cur to protect $\mathrm{Al}$ at high temperature of $90^{\circ} \mathrm{C}$ reduces the possibility of physisorption [12]. It has been assumed that organic inhibitor molecules establish their inhibition action via the adsorption of the inhibitor onto the metal surface. The adsorption process is affected by the chemical structures of the inhibitors, the nature and charged surface of the metal and the distribution of charge over the whole inhibitor molecule. In general, due to the complex nature of adsorption and inhibition of a given inhibitor, it is impossible for a single adsorption mode to take place between inhibitor and metal surface. 
In another study, Hazra et al. [34] stated: "The present study indeed shows that Curcumin monomers form clusters through the association of phenyl rings. The strong propensity towards the association of Curcumin molecules for each other favors the formation of significantly large cluster.” The hydrophobic nature of the phenyl in Cur with hydrogen bond formation ability of the side groups is proposed to be the reasons for its aggregation in water which agrees with the Jagannathan et al. [25] model of the "supramolecular arrangement bound together by H-bonding”. The conclusions of Hazra et al. [34] and Jagannathan et al. [25] are in agreement with the study by Elmsellem et al. [22], the density distributions of the frontier molecular orbital (HOMO and LUMO) show that Curcumin on iron adsorbs through the active centers oxygen and $\pi$ electrons of the Curcumin ring. These have high electronic density and are known to be active centers of metal adsorption. The adsorption results agree well with the FTIR conclusion that the protective film consists of the $\mathrm{Al}^{3+}$-Curcumin complex.

\section{Conclusion}

Curcumin is used successfully as a green corrosion inhibitor at quasi-cooking conditions $\left(90^{\circ} \mathrm{C}\right)$ to inhibit leaching from Aluminum in different vegetable and meat solutions. The corrosion inhibition efficiencies of Cur decreased slightly in the presence of $\mathrm{NaCl}$. The corrosion inhibition efficiencies of Cur increased with increasing inhibitor concentration. Reasonably good agreement was observed between weight loss and Atomic absorption techniques. The effect of immersion time from AA method indicates that Cur Inhibitor is adsorbed mostly at the earlier stages. The FTIR spectrum leads to the conclusion that the protective film consists of the $\mathrm{Al}^{3+}$ Curcumin complex. Only chemisorption seemed to contribute to the adsorptive behavior of Cur inhibitor and the adsorption process obeyed Langmuir adsorption isotherm. The value of the adsorption constant $\left(K_{a d s}\right)$ and the free energy of adsorption $\left(\Delta G_{a d s}^{o}\right.$ ) for the solutions of Zuc + Cur is higher than in the presence of Zuc + Cur + $\mathrm{NaCl}$. The chelating properties of Cur render it useful in a multitude of applications in aqueous or organic polar solutions due to the presence of carbonyl groups, OH group and the ability of Cur to be adsorbed on the Al surface. In cooking, using a small amount of Curcumin decreased leaching from Aluminum cook wares into food by $60 \%$ - $80 \%$ depending upon the type of food which decreased the dangers of using Aluminum cook wares.

\section{Acknowledgements}

This research project was supported by a grant from the Research Center of the Female Scientific and Medical Colleges, Deanship of Scientific Research, King Saud University. The help of research assistance Asma Al Angery is highly valued in doing part of the gravimetric work.

\section{References}

[1] Gitelman, H. (1989) Aluminum and Health. Marcel Dekker Inc., New York.

[2] Winship, K. (1993) Toxicity of Aluminum: A Historical Review, Part 1. Adverse Drug Reactions Toxicology Review, 11, 123-141.

[3] Soni, M.G., White, S.M., Flamm, W.G. and Burdock, G.A. (2001) Safety Evaluation of Dietary Aluminum. Regulatory Toxicology and Pharmacology, 33, 66-79. http://dx.doi.org/10.1006/rtph.2000.1441

[4] WHO/FAO (2007) Expert Committee on Safety Evaluation of Certain Food Additives and Contaminants. Food Additives Series 58, WHO, Geneva, 119-207.

[5] Martell, A.E., Motekaitis, R.J. and Smith, R.M. (1990) Aluminum Complexes of Hydroxyaliphatic and Hydroxyaromatic Ligands in Aqueous Systems-Some Problems and Solutions. Polyhedron, .9, 171-187. http://dx.doi.org/10.1016/S0277-5387(00)80566-5

[6] Al-Saleh, I. and Shinwari, N. (1996) Aluminum in Saudi Children. Biometals, 9, 385-392. http://dx.doi.org/10.1007/BF00140608

[7] Ščančar, J., Stibilj, V. and Miačič, R. (2004) Determination of Aluminum in Slovenian Foodstuffs and Its Leachability from Aluminum Cookware. Food Chemistry, 85, 151-157. http://dx.doi.org/10.1016/j.foodchem.2003.07.028

[8] Verissimo, M.I.S., Oliveira, J. and Gomes, M. (2006) Leaching of Aluminum from Cooking Pans and Food Containers. Sensors \& Actuators, B: Chemical, 118, 192-197. http://dx.doi.org/10.1016/j.snb.2006.04.061

[9] Al Juhaiman, L.A. (2010) Estimating Aluminum Leaching from Aluminum Cook Wares in Different Meat Extracts and Milk. Journal of Saudi Chemical Society, 14, 131-137. http://dx.doi.org/10.1016/j.jscs.2009.12.020

[10] Al Juhaiman, L.A. (2012) Estimating Aluminum Leaching from Aluminum Cook Wares in Different Vegetable Extracts. International Journal of Electrochemical Science, 7, 7283-7294. 
[11] McCafferty, E. (2009) Introduction to Corrosion Science. Springer, New York.

[12] DąBrowski, A. (2001) Adsorption from Theory to Practice. Advance Colloid and Interface, 93, 135-224. http://dx.doi.org/10.1016/S0001-8686(00)00082-8

[13] Parthasarathy, V.A., Chempakam, B. and Zachariah, T.J. (2008) Chemistry of Spices. CABI, London. http://dx.doi.org/10.1079/9781845934057.0000

[14] Aggarwal, B.B., Sundaram, C., Nikita, M. and Haruyo, I. (2007) Curcumin: The Indian Solid Gold. Advances in Experimental Medicine and Biology, 595, 1-75. http://dx.doi.org/10.1007/978-0-387-46401-5_1

[15] FAO (2004) Report Chemical and Technical Assessment 61st JECFA.

[16] Fouda, A.S. and Elattar, K.M. (2012) Curcumin Derivatives as Green Corrosion Inhibitors for $\alpha$-Brass in Nitric Acid Solution. Journal of Materials Engineering and Performance, 21, 2354-2362. http://dx.doi.org/10.1007/s11665-012-0160-0

[17] Abdul Halim, A., Abu Bakar, F., Abidin, N.Z., Awang, M., Wahab, I. and Ithnin, A. (2011) Effect of the Acidic Food Flavors and Turmeric towards Aluminium Leachability. Australian Journal Basic Applied Science, 5, 597-601.

[18] Rajendran, S., Duraiselvi, K., Prabhakar, P., Pandiarajan, M., Tamilmalar, M. and Joseph Rathish, R. (2013) Corrosion Resistance of Commercial Aluminum in Simulated Concrete Pore Solution in Presence of Curcumin Extract. Europian Chemical Bulletin, 2, 850-854.

[19] Johnsirani, V., Sathiyabama, J., Rajendran, S. and Nagalakshmi, R. (2013) Curcumin Dye as Corrosion Inhibitor for Carbon Steel in Sea Water. European Chemical Bulletin, 2, 401-406.

[20] Al-Fakih, A.M., Aziz, M. and Sirat, H.M. (2015) Turmeric and Ginger as Green Inhibitors of Mild Steel Corrosion in Acidic Medium. Journal of Material Environmental Science, 6, 1480-1487.

[21] Nasibi, M., Mohammady, M., Ashrafi, A., Khalaji, A.D., Moshrefifar, M. and Rafiee, E. (2014) Nanosized Scale Roughness and Corrosion Protection of Mild Steel in Hydrochloric Acid Solution and in the Presence of Turmeric (Curcuma Longa) Extract as a Green Corrosion Inhibitor: FTIR, Polarization, EIS, SEM, EDS, AFM Studies and NN Modeling. Journal of Adhesion Science and Technology, 28, 2001-2015. http://dx.doi.org/10.1080/01694243.2014.941053

[22] Elmsellema, H., Youssouf, M.H., Aounitia, A., Ben Haddab, T., Chetouania, A. and Hammouti, B. (2014) Adsorption and Inhibition Effect of Curcumin on Mild Steel Corrosion in Hydrochloric Acid. Russian Journal of Applied Chemistry, 87, 744-753. http://dx.doi.org/10.1134/S1070427214060147

[23] Kurien, B.T., Singh, A., Matsumoto, H. and Scofield, R.H. (2007) Improving the Solubility and Pharmacological Efficacy of Curcumin by Heat Treatment. Assay Drug and Developement Technology, 5, 567-576. http://dx.doi.org/10.1089/adt.2007.064

[24] Sneharani, A.H., Karakkat, J.V., Singh, S.A. and Rao, A.G. (2010) Interaction of Curcumin with $\beta$-Lactoglobulin-Stability, Spectroscopic Analysis, and Molecular Modeling of the Complex. Journal of Agricultural Food Chemistry, 58, 11130-11139. http://dx.doi.org/10.1021/jf102826q

[25] Jagannathan, R., Abraham, P.M. and Poddar, P. (2012) Temperature-Dependent Spectroscopic Evidences of Curcumin in Aqueous Medium: A Mechanistic Study of Its Solubility and Stability. Journal of Physical Chemistry B, 1453314540. http://dx.doi.org/10.1021/jp3050516

[26] Sharma, K., Agrawal, S.S. and Gupta, M. (2012) Development and Validation of UV Spectrophotometric Method for the Estimation of Curcumin in Bulk Drug and Pharmaceutical Dosage Forms. M. International Journal of Drug Development \& Research, 4, 375-380.

[27] Al-Mayouf, A., Al Juhaiman, L. and Al Sohaybani, A. (2007) Corrosion of Aluminum in Ascorbic, Citric and Tartaric Acid w/without Chloride Ions. Anti-Corrosion Methods \& Materials, 55, 79-83. http://dx.doi.org/10.1108/00035590810859458

[28] Joshi, S.P., Toma, R.B., Medora, N. and O’Connor, K. (2003) Detection of Aluminium Residue in Sauces Packaged in Aluminum Pouches. Food Chemistry, 83, 383-386. http://dx.doi.org/10.1016/S0308-8146(03)00099-2

[29] McCafferty, E. (2003) Sequence of Steps in the Pitting of Aluminum by Chloride Ions. Corrosion Science, 45, 14211438. http://dx.doi.org/10.1016/S0010-938X(02)00231-7

[30] Pyun, S. and Lee, W. (2001) The Effect of Cl-Ion Incorporation into Native Oxide Film on Pure Aluminum in Neutral Chloride Solution on Pit Initiation. Corrosion Science, 43, 353-363. http://dx.doi.org/10.1016/S0010-938X(00)00077-9

[31] Böröcz-Szabó, M. (1976) Corrosion of Steel and Aluminum Construction Materials in Different Food Media. ActaAlimentaria, 5, 227-240.

[32] Subhan, M.A., Alam, K., Rahaman, M.S., Rahman, M.A. and Awal, M.R. (2014) Synthesis and Characterization of Metal Complexes Containing Curcumin $\left(\mathrm{C}_{21} \mathrm{H}_{20} \mathrm{O}_{6}\right)$ and Study of Their Anti-Microbial Activities and DNA Binding Properties. Journal of Scientific Research, 6, 97-109. 
[33] Kairi, N.I. and Kassim, J. (2013) The Effect of Temperature on the Corrosion Inhibition of Mild Steel in 1 M HCl Solution by Curcuma Longa Extract. International Journal of Electrochemical Science, 8, 7138-7155.

[34] Hazra, M.K., Roy, S. and Bagch, B. (2014) Hydrophobic Hydration Driven Self-Assembly of Curcumin in Water: Similarities to Nucleation and Growth under Large Metastability, and an Analysis of Water Dynamics at Heterogeneous Surfaces. Journal of Chemical Physics, 141, 18C501-18C508. http://dx.doi.org/10.1063/1.4895539 